\title{
AXISYMMETRIC TEXTURES IN ALUMINA
}

\author{
NICHOLAS W. MEDENDORP, JR., KEITH L. KRUGER \\ and KEITH J. BOWMAN \\ Purdue University, School of Materials Engineering, W. Lafayette, IN \\ DORTE JUUL JENSEN and O. TOFT SØRENSEN \\ Ris $\varnothing$ National Laboratory, Roskilde, Denmark
}

(Received 20 August 1994; in final form 18 October 1994)

\begin{abstract}
The occurrence of axisymmetric textures prevails over a wide range of processing approaches for alumina-based materials. Mechanisms ranging from dislocation slip, recrystallization, anisometric grain rotation and grain growth all can contribute to the development of textures with similar characteristics. This paper documents neutron texture measurements of axisymmetric textures in hot-pressed, hot-forged and tape-cast alumina. Strong basal textures were introduced in the tape-cast samples during long term annealing in finer, non-tabular aluminas if glass and dopant additions are introduced. The implications of these results versus prior reports of textures in alumina and alumina matrix composites are discussed.
\end{abstract}

KEY WORDS: Aluminum oxide, hot-forging, axisymmetric textures, tape casting, hot pressing

\section{INTRODUCTION}

Prior research has demonstrated that basal fiber textures are produced in aluminas processed with almost any directional history. Tape-casting of alumina results in alignment of platey grains that apparently dominate sintering to produce strong preferred orientations (Böcker et al., 1991, Böcker et al., 1994; Huber et al., 1994). A similar process has been employed by Handwerker and coworkers wherein 10-20 $\mathrm{mm}$ diameter single crystal platelets are included in the slurry mixture to act as seeds for subsequent oriented growth (Cline et al., 1994, Medendorp et al., 1994). The incorporation of anorthite glass and rare earth dopants can be used to influence grain growth and thereby alter the development and character of textures and microstructures (Kim et al., 1994). Both strategies show that grain growth is a significant factor in texture evolution. Recent work on oriented growth of alumina platelets in alumina-zirconia composites (Roeder et al., 1994) and seeded growth of AIN with SiC platelets (Sandlin et al., 1994) demonstrates the potential of incorporated seeds in controlling ceramic textures and microstructures.

Growth processes that enhance textures are also expected in ceramic materials undergoing hot deformation. Basal textures that arise during hot deformation of alumina at $1600-1900^{\circ} \mathrm{C}$ have been primarily attributed to easy basal slip (Ma and Bowman, 1991; Ma, Lee and Bowman, 1994). Thus far, all aluminas successfully oriented by hot deformation contained adequate impurities to support a substantial glass phase or include second phase additions such as zirconia that promote superplastic deformation by inhibiting grain growth. One role of the glass phase in successful forging experiments may be to accommodate basal slip by providing a deformation mechanism other than slip. In superplastic deformation of zirconia-alumina composites, the mutual insolubility 
of zirconia and alumina and a fine distribution of sub-micron zirconia provided sufficient grain boundary pinning to suppress grain growth and maintain grain boundary sliding processes (Chen, 1991; Ma, 1994). In these superplastic materials little texture is evident as is expected for materials containing a relatively rigid reinforcement phase.

The reproducibility of texture measurements is an important aspect of quality control efforts wherein material properties are related to textures. In conventional x-ray texture analysis, the combination of this particular texture, the low symmetry of alumina (trigonal) and the low structure factor of available basal reflections result in some uncertainty regarding the actual intensity of the basal texture component when the texture is strong.

Cline et al. (1994) have used an approach employing inverse pole figure techniques combined with the iterative approach of Rietveld analysis. This application of Rietveld calculations refines a simulated set of $\mathrm{x}$-ray powder diffraction data to a specific degree of orientation. Some advantages over conventional pole figure analysis include use of many peaks. On the other hand, the single point in the sample orientation space and the limited number of peaks available covers only a small region of orientation space. Wenk (1994) has discussed the potential benefits of coupling the iterative refinement of Rietveld analysis with calculation strategies incorporating the orientation distribution function, with particular emphasis on multiphase and low crystal symmetry materials.

Bunge and coworkers have addressed the problem of pole figure measurements using neutron diffraction calculations of a large number of complete pole figures determined using peak intensities and spherical harmonic calculations (Böcker, et al., 1991; 1994). Besides higher relative intensity for the basal reflections, undoubtedly the elimination of defocussing corrections also aids in obtaining accurate pole figures. Nonetheless, measurement of many neutron pole figures with conventional point-by-point data collection is certainly prohibitive for routine measurements. Additionally, the accuracy of reports in multiples of a random distribution (MRD) for basal fiber texture greater than 10-15 MRD becomes questionable and peak half-widths may become more meaningful (Böcker et al., 1994; Huber et al., 1994). Furthermore, if the documented challenge of accurately reporting the basal texture is considered, the potential accuracy of pole figure measurements for composites wherein pole figures from the two phases overlap in d-spacing may be in question.

The goal of this investigation was to make careful neutron pole figure measurements on sample sets with very different histories but apparently very similar textures. In particular, the specimens from one set were oriented primarily by grain growth and another oriented primarily by hot deformation. The neutron pole figures were measured at Ris $\varnothing$ National Laboratory in Denmark using a position sensitive detector system that is innately biased to measurement of a large number of points at low tilt $(\chi)$ angles. Thus, concentricity and alignment on the fiber texture component could be readily determined.

\section{EXPERIMENTAL PROCEDURE}

\section{Tape-Cast Samples}

The $\mathrm{Al}_{2} \mathrm{O}_{3}$ tape cast specimens were produced using AKP - 30 (Sumitomo Chemical America) powder along with the addition of a binder (see Cline, 1994; Kim, 1994). The $\mathrm{Al}_{2} \mathrm{O}_{3}$ also had additions of $4 \%$ by weight anorthite glass $\left(\mathrm{CaAl}_{2} \mathrm{Si}_{2} \mathrm{O}_{8}\right)$ and cerria 
$\left(\mathrm{CeO}_{2}\right)$. The $\mathrm{Al}_{2} \mathrm{O}_{3}$ slurry was tape-cast via doctor blade method, to $40 \mathrm{~mm}$ thick. Lamination of the tapes occurred by warm pressing $\left(80^{\circ} \mathrm{C}\right) 40$ layers of tape to $\sim 50 \%$ reduction in thickness. Sintering of the samples took place at $1600^{\circ} \mathrm{C}$ in air for 25 hours. Ceria was employed as a dopant effecting anisotropic crystal growth of $\mathrm{Al}_{2} \mathrm{O}_{3}$ in molten fluxes.

\section{Hot-Deformed Samples}

All samples were composed of A-16 (ALCOA) $\mathrm{Al}_{2} \mathrm{O}_{3}$ powder with 0.25 wt\% $\mathrm{MgO}$ added to control grain size. Primary impurities of the $\mathrm{Al}_{2} \mathrm{O}_{3}$ powder were approximately 0.08 wt $\% \mathrm{Na}_{2} \mathrm{O}, 0.025 \mathrm{wt} \% \mathrm{SiO}_{2}, 0.01 \mathrm{wt} \% \mathrm{Fe}_{2} \mathrm{O}_{3}, 0.001 \mathrm{wt} \% \mathrm{~B}_{2} \mathrm{O}_{3}$, and $0.05 \mathrm{wt} \%$ $\mathrm{MgO}$. A hot-pressed sample approximately $6 \mathrm{~cm}$ in diameter was produced by loose powder compaction directly in a graphite die cavity. The alumina was sintered for 30 minutes under an applied stress of $27 \mathrm{MPA}$ at $1700^{\circ} \mathrm{C}$ under a vacuum of $0.2 \mathrm{~Pa}$.

For the hot-forged specimen, a billet was initially cold-pressed at approximately 28 MPa to nearly $34 \%$ theoretical density. The sample was presintered at $1150^{\circ} \mathrm{C}$ for 1 hour to facilitate handling. The cold pressed sample was subsequently sinter-forged to $\sim 73 \%$ height reduction at approximately $28 \mathrm{MPa}$ at $1700^{\circ} \mathrm{C}$ with graphite dies to achieve an axisymmetric compression condition. For both the hot-pressed and hot-forged specimens, graphite foil was applied to lubricate die surfaces in contact with alumina. For neutron diffraction measurements, specimens were cut from the center of the samples on a plane normal to the applied stress.

\section{Texture Measurements}

Complete pole figures were measured at Ris $\varnothing$ National Lab on the DR3 neutron reactor with the double axis spectrometer TAS 3 . The spectrometer was equipped with a linear position sensitive detector and Euler goniometer as described by Juul Jensen et al. (Juul Jensen, 1989). The samples were mounted in the Euler goniometer with the tape casting or hot pressing plane parallel to the $\mathrm{c}=0^{\circ}$ plane. Complete pole figures for the hexagonal 116,113 , and 006 reflections, reflections that do not substantially overlap with the $\mathrm{SiC}$ reinforcements found in some whisker and platelet composites, and several orientations for background substraction were measured over roughly $120^{\circ}$ of rotation about the symmetry axis. The 1097 points for the basal pole figure in the neutron measurements were inspected to identify the true texture maximum and adjusted with the texture maximum set as the true point of $\mathrm{c}=0^{\circ}$ to insure concentricity. This deviation in the maximum was less than $2^{\circ}$ in all specimens reported for this paper. Then each of the sets of pole figure data was transformed into a $5^{\circ}-\mathrm{c}$ by $5^{\circ}-\varnothing$ grid of 324 points over one octant of orientation space and corrected for background. Orientation distribution functions (ODFs) were calculated via WIMV analysis using the Preferred Orientation Package-Los Alamos (POPLA) software to generate the basal pole figures shown in this paper with an assumption of trigonal crystal symmetry and orthorhombic sample symmetry (Kallend, 1991). Accuracies of better that $4 \%$ were obtained for all calculations in less than ten iterations of the WIMV algorithm. The ODFs for the stronger textures in the hot-forged and tape-cast materials were within a WIMV accuracy of $1 \%$. Calculations using hexagonal symmetry and the WIMV and spherical harmonic calculations of POPLA resulted in slightly better recalculation of the basal pole figures such that the recalculated 001 pole figures had maximum intensities that were not quite as diminished from the experimental 006 pole figures, but are not provided in this paper (Medendorp, 1994). 


\section{RESULTS}

Experimental and recalculated pole figures of the hot-forged sample are shown in Figure 1. The axisymmetry of the basal textures are clear as is the difference in the maximum of the basal pole figure. Nonetheless, there is very little overall difference in the three sets of pole figures if the data is replotted as averaged sections of the axisymmetric pole figures. The overall difference in multiples of a random distribution (MRD) is very small on every pole figure except for the basal one (see Figure 2). The difference between the experimental and recalculated poles figures can be changed by slightly altering the orientation identified as the symmetry axis for each pole figure, but this apparently produces no significant difference in the recalculated pole figures.

The calculated pole figures for the hot-pressed sample, the hot-forged sample and the tape-cast sample doped with anorthite glass and $\mathrm{CeO}_{2}$ are shown in Figure 3. All three samples showed near-axisymmetry. The basal texture maximum is about 10 MRD lower for the hot-pressed versus the hot-forged and tape cast sample.

\section{DISCUSSION}

The texture intensity of the basal pole figures reported for the hot-pressed and hotforged materials is somewhat higher than previously reported by Ma and Bowman (1991) for materials processed under similar conditions and with similar textures as suggested by powder diffraction results. The discrepancy between the two data sets is most likely

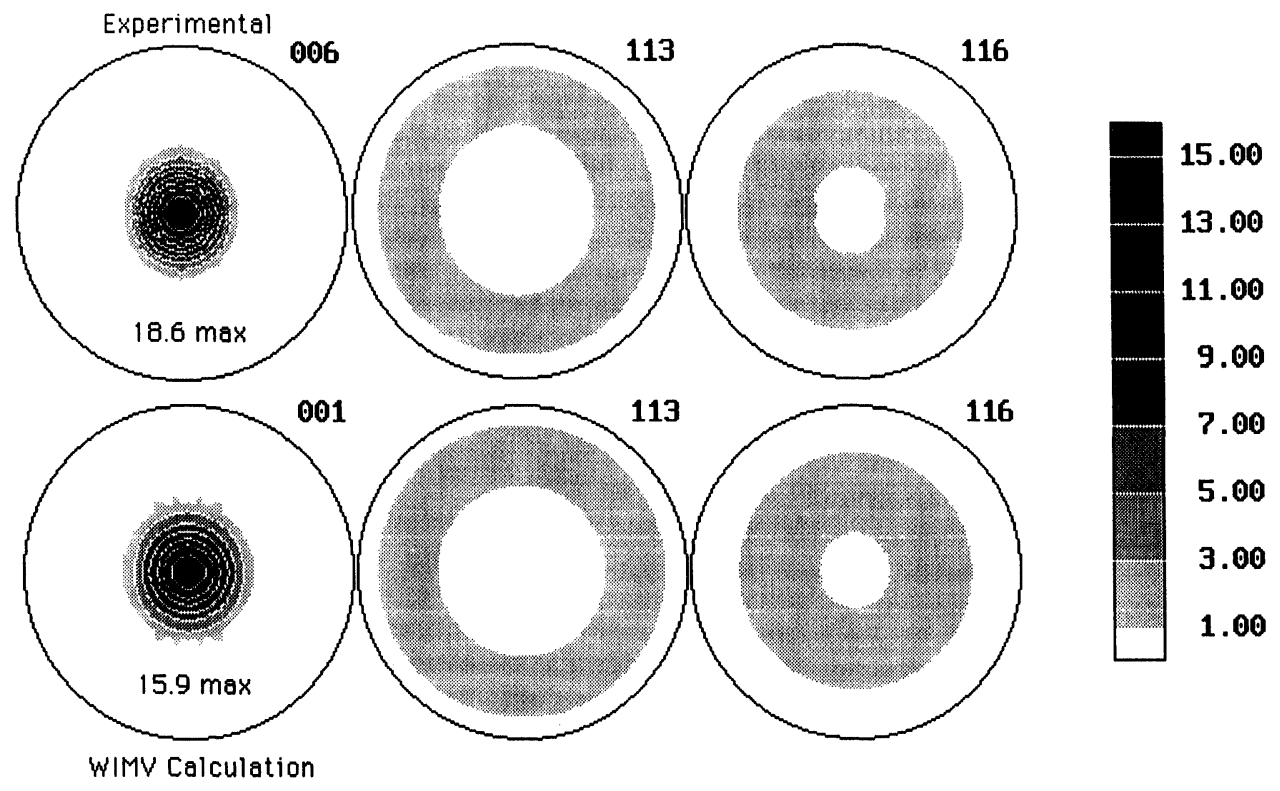

Figure 1 The experimental and WIMV calculated pole figures for the hot-forged material. 

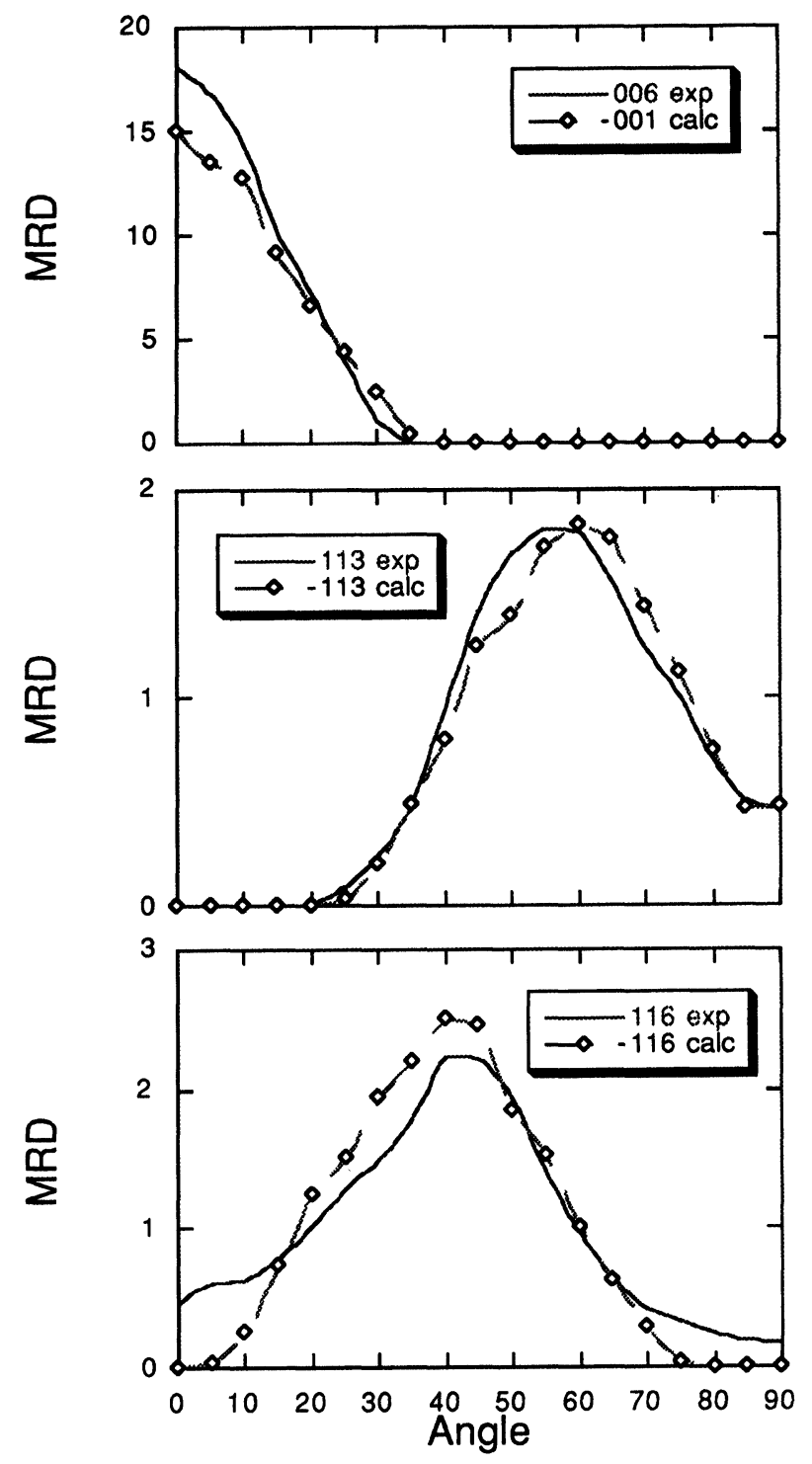

Figure 2 Averaged axisymmetric sections of the experimental (exp) and calculated (calc) pole figures from Figure 1.

a result of the use of x-ray diffraction to determine the texture maximum. The combination of incomplete pole figures and the low intensity of the basal peaks in $\mathrm{x}$-ray diffraction make accurate estimates of the texture intensity as a specific value of MRD very difficult. 


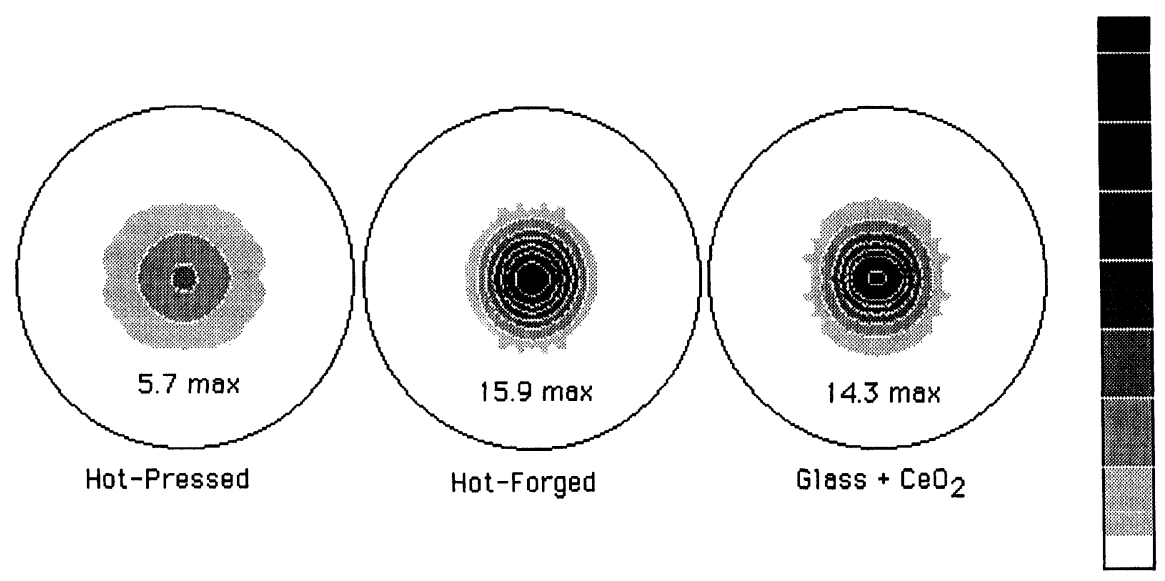

Figure 3 The calculated pole figures of the hot-pressed, hot-forged and tape-cast (with anorthite glass and $\mathrm{CeO}_{2}$ ) samples.

Additionally, the calculations used to produce Figures 1 and 2 demonstrated that any small changes in the pole figure data can be manifested very strongly in the intensity of the basal texture component. Bunge and coworkers have also shown similar problems with x-ray data and strong axisymmetric textures. Thus, we would have to agree that a strategy based on peak distribution shapes (Böcker et al., 1994; Huber et al., 1994) or maybe fitted model functions might be more accurate for purposes of comparison. In our calculations on alumina, using sets of complete pole figures that exclude the basal one, reproduction of the basal maximum is very inaccurate. Even calculations assuming hexagonal symmetry in the WIMV and spherical harmonic technique do not accurately reproduce the basal pole figure. Thus, it seems essential to measure an accurate basal pole figure to accurately calculate an ODF. This does not have a very positive implication for similar textures in trigonal materials for which even a neutron basal pole figure might be unavailable due to structure factor or an overlapping peak. Although routines for iterative refinement in multi-phase textures are available, it is likely that overlap of a strong reflection in the second phase might destroy any potential for an accurate calculation. One could also argue that the experimental basal pole figure itself is sufficient information in strong axisymmetric basal textures, since the iterative algorithms do not reliably reproduce the texture intensity of the basal pole figure when the other experimental pole figures are included in the calculation.

The textures from the tape cast and hot-forged materials show no systematic differences between the two materials; both posses primarily simple basal textures despite very different processing histories. The slightly higher intensity of the basal texture in the forged sample was also evident from powder diffraction measurements. Since both materials did posses some glassy phase, it is apparent that the alignment of grains in the hot-forged material occurs quite rapidly. As shown previously by Ma and coworkers (1994), the degree of texture development in hot-forging is accentuated by performing the forging at lower temperature. Certainly this is contrary to any argument that suggests that the textures result primarily from rigid-body rotation 
combined with grain growth. On the other hand, the results for the tape cast material demonstrate that the addition of glass and dopants can produce strong basal textures in aluminas that are not considered to have a platey character.

\section{Acknowledgement}

Tape cast samples prepared by James P. Cline, Carol A. Handwerker, Mark D. Vaudin, and John E. Blendell from National Institute of Standards and Technology. This research was supported by the United States National Science Foundation through Grant No. DMR-91-21948.

\section{References}

Böcker, A., Brokmeier, H. G. and Bunge H. J. (1991). "Description of Preferred Orientation in $\mathrm{Al}_{2} \mathrm{O}_{3}$ Ceramics," Journal of the European Ceramic Society, 7, pp. 187-94.

Böcker, A., Bunge H. J., Huber J. and W. Krahn (1994). "Texture Formation in $\mathrm{Al}_{2} \mathrm{O}_{3}$ Substrates," J. European Ceramic Society, 14, In Press.

Chen, W-. and Xue, L (1990). "Development of Superplastic Structural Ceramics," Journal of the European Ceramic Society, 73, pp. 2585-609.

Cline, J-. et al., (1994). "Texture Measurement of Sintered Alumina Using the March-Dollase Function," Advances in X-Ray Diffraction, In Press.

Huber, J., Krahn, W., Ernst, J., Böcker, A. and Bunge, H. J. (1994). "Texture Formation in $\mathrm{Al}_{2} \mathrm{O}_{3}$ Substrates," Mat. Sci. Forum, Vol. 157-162, pp. 1411-1416.

Kallend, J. S., Kocks, U. F., Rollett, A. D. and Wenk, H-R. (1991). "Operational Texture Analysis," Material Science and Engineering A132, pp. 1-11.

Kim, D-Y. Wiederhorn, S. W., Hockey, B. J., Handwerker, C. A. and Blendell, H. J. (1994). "Stability and Surface Engeries of Wetted Grain Boundaries in Aluminum Oxide," Journal of the European Ceramic Society, 73, pp. 444-53.

Jensen, Juul, D. and Leffers, T. (1989). "Fast Texture Measurements Using a Position Sensitive Detector," Texture and Microstructures., 10, pp. 361-369.

Medendorp, N. W., Bowman, K. J. Handwerker, C. A. and Blendell, J. (1994). "Neutron Textures of Axisymmetric Alumina and Alumina Composites," Unpublished Results.

Ma, Y. and Bowman, K. J. (1991). "Texture in Hot Pressed or Forged Alumina," Journal of the European Ceramic Society, 74, pp. 2941-44.

Ma, Y., Kruger, K.L. and Bowman, K.J. (1994). "How Deformation Textures in Slip-Limited Materials," in Advances in Hot Deformation Textures and Microstructures, edited by J. J. Jonas, T. R. Bieler and K. J. Bowman, TMS, Warrendale, PA. pp. 503-519.

Roeder, R. K., Bowman, K. J. and Trumble, K. P. (1994?). "Texture and Microstructure Development in $\mathrm{Al}_{2} \mathrm{O}_{3}$ Platelet Reinforced Ce- $\mathrm{ZrO}_{2} / \mathrm{Al}_{2} \mathrm{O}_{3}$ Laminates Produced by Centrifugal Consolidation," Submitted to this volume.

Sandlin, M. S. and Bowman, K. J. (1994). "Texture in SiC-AIN Composites," MRS Symposium Proceedings, Boston Mass., Covalent Ceramics II. Non-Oxides, edited by Andrew R. Barron et al., Mat. Res. Soc. Symp. Proc., 327, pp. 263-269.

Wenk, H-R., Mathies, S. and Lutterotti, L. (1994). "Texture Analysis from Diffraction Spectra," Mat. Sci. Forum., Vol. 157-162, pp. 473-480. 